\title{
Cyclooxygenase-2 and B-cell lymphoma-2 expression in cystitis glandularis and primary vesicle adenocarcinoma
}

\author{
Zhongxing $\mathrm{Li}^{1 \dagger}$, Guangcheng Ge ${ }^{1 \dagger}$, Rui Feng ${ }^{1 \dagger}$, Dan Wu${ }^{1}$, Bin Shen ${ }^{1}$, Xing Wang ${ }^{1}$, Yan Cui ${ }^{1}$, Junrong $\mathrm{Li}^{2}$ \\ and Xiaobing $\mathrm{Ju}^{3^{*}}$
}

\begin{abstract}
Background: Although cystitis glandularis (CG) is a common benign urinary bladder epithelial abnormality, it remains unclear whether CG is a premalignant lesion. Cyclooxygenase-2 (COX-2) and B-cell lymphoma-2 (Bcl-2) overexpression has recently been reported as a potential tumor initiator or promoter. We evaluated and compared COX-2 and Bcl-2 expression in CG, chronic cystitis (CC), and primary vesicle adenocarcinoma (ADC) tissues.

Methods: We conducted a retrospective study to investigate COX-2 and BCl-2 levels in CG and ADC. We obtained tissue samples from 75 patients (including 11 cases of CC, 30 typical cases of CG (CGTP), 30 cases of intestinal CG (CGIT), and 4 cases of ADC) between 1989 and 2009 from the Surgical Pathology Archives of the No. 2 People's Hospital of Zhenjiang, affiliated with Jiangsu University. COX-2 and BCl-2 immunohistochemical staining was performed on all tissues. Nine normal bladder epithelial specimens were evaluated as control samples. Correlations between COX-2 and BCl-2 expression in CG were also analyzed.

Results: COX-2 and Bcl-2 expression was higher in the ADC group compared to other groups $(p<0.05)$. COX-2 and $\mathrm{BCl}-2$ levels were higher in the CGIT group compared to the CGTP group ( $p=0.000$ for both). The CGIT and CGTP groups both showed higher COX-2 expression compared to the CC group ( $p=0.000$ for both). There was no difference in Bcl-2 expression between the CGTP and CC groups ( $p=0.452$ ). Additionally, the difference in COX-2 and BCl-2 expression between the control and CC groups was also insignificant ( $p=0.668$ and $p=0.097$, respectively). Finally, we found that COX-2 and BCl-2 levels were positively related ( $r=0.648, p=0.000)$.

Conclusion: COX-2 and BCl-2 overexpression in the CG group suggests that $C G$, particularly the intestinal type, may be a premalignant lesion that converts into a tumor in the presence of carcinogens.
\end{abstract}

Keywords: Cyclooxygenase-2, Bcl-2, Cystitis

\section{Background}

Cystitis glandularis (CG) is a common benign epithelial abnormality that occurs in the presence of chronic inflammation [1,2]. Based on morphology and behavior, CG has been subdivided into two subtypes. Typical CG (CGTP) is characterized by nests of columnar epithelial cells within the bladder lamina propria that form glandular structures. The intestinal type (CGIT) has similar

\footnotetext{
* Correspondence: doctorjxb73@njmu.edu.cn

${ }^{\dagger}$ Equal contributors

${ }^{3}$ Department of Urology, The First Affiliated Hospital of Nanjing Medical University, 300 Guangzhou Road, Nanjing 210029, China

Full list of author information is available at the end of the article
}

glandular architecture in the lamina propria but contains abundant mucin-secreting goblet cells in the lining epithelium [3]. Although the cause of CG is debatable [4], it is generally agreed that in the presence of chronic inflammation, the bladder mucosa becomes hyperproliferative. When proliferation projects into the lamina propria, epithelial nests (von Brunn's nests) [5] and cystitis cystica or glandular lesions (CG) form [5,6]. CG, particularly the intestinal type, has been described as premalignant; however, not all studies agree with this conclusion [3,7]. Due to rare reported instances of CG progression to adenocarcinoma or CG associated with

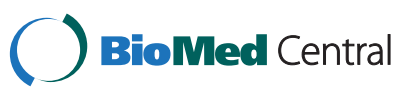

(c) 2014 Li et al.; licensee BioMed Central Ltd. This is an open access article distributed under the terms of the Creative Commons Attribution License (http://creativecommons.org/licenses/by/2.0), which permits unrestricted use, distribution, and reproduction in any medium, provided the original work is properly cited. 
adenocarcinoma, the relationship between CG and subsequent bladder adenocarcinoma remains unclear.

Cyclooxygenase is an important enzyme that catalyzes the conversion of arachidonic acid to prostaglandin. COX-1 is constitutively expressed in most tissues and regulates multiple physiological processes. In contrast, COX-2 is frequently undetectable in normal tissues, but can be induced by a variety of stimuli, including mitogens, cytokines, growth factors, and hormones, thereby resulting in inflammation and cellular proliferation [8]. COX-2 overexpression is observed in chronic inflammation as well as in various tumors, including bladder, prostate, colon, and lung [9-12]. To this end, we assessed the differential expression of COX-2 in normal bladder transitional cell tissue, chronic cystitis, two subtypes of CG, and bladder adenocarcinoma tissue. In addition, we determined if COX-2 expression is associated with expression of $\mathrm{Bcl}-2$, a regulator and marker of apoptosis.

\section{Methods}

\section{Patient samples}

Tissues from 75 patients, including 60 cases of CG, 11 cases of chronic cystitis (CC), and 4 cases of primary vesicle adenocarcinoma (ADC), were obtained from the Surgical Pathology Archives of the No. 2 People's Hospital of Zhenjiang, affiliated with Jiangsu University between 1989 and 2009. Normal bladder specimens from nine subjects who underwent cystectomy for benign causes were used as controls. The Institutional Review Board of Nanjing Medical University (Nanjing, China) approved this study. At the time of patient recruitment, written informed consent was obtained from all participants. We classified CG into CGTP and CGIT based on routine hematoxylin and eosin-stained sections. One of the ADC patients had the intestinal type of CG and interrupted use of antibiotics rather than intravesical instillation of the anticancer agent. Another patient had neurogenic bladder with suprapubic cystostomy for fifteen years. The other two patients had classic bladder exstrophy with an unsuccessful initial closure.

\section{Immunohistochemistry and staining evaluation}

Sections $(5 \mu \mathrm{m}$ thick) were cut from formalin-fixed, paraffin-embedded tissue blocks and stained with hematoxylin and eosin. Additional sections from appropriately selected blocks were cut for use in immunohistochemical analyses as described previously [13,14]. Two primary antibodies were used for immunochemical staining: monoclonal antibodies against COX-2 (monoclonal mouse anti-human D12; Santa Cruz Biotechnology, USA) and Bcl-2 (monoclonal mouse anti-human; Dako, Carpinteria, USA). Briefly, sections were baked for 2 hour at $72^{\circ} \mathrm{C}$ and deparaffinized by sequential immersion in xylene, 95\% ethanol, $80 \%$ ethanol, and distilled water for $5 \mathrm{~min}$ each.
Next, slides were placed in an autoclave containing antigen retrieval solution $(0.1 \mathrm{M}$ citrate buffer from $\mathrm{BDH}$ at $\mathrm{pH} \mathrm{6.0)} \mathrm{for} 2 \mathrm{~min}$ at $121^{\circ} \mathrm{C}$. Diluted primary antibodies $(100 \mu \mathrm{l})$ were applied to the sections and slides were incubated in a humid chamber for $2 \mathrm{~h}$ at $37^{\circ} \mathrm{C}$. Slides were rinsed gently with PBS and placed in a fresh PBS bath for $5 \mathrm{~min}$. Next, one or two drops of diluted biotinylated secondary goat anti-mouse antibodies (Dako Cytomation) were applied to the sections and the slides were incubated in a humid chamber for $2 \mathrm{~h}$ at $37^{\circ} \mathrm{C}$. After rinsing, one or two drops of streptavidin-horseradish peroxidase reagent (Dako Cytomation) was added to the sections and slides were incubated for $30 \mathrm{~min}$ at $37^{\circ} \mathrm{C}$. Next, the prepared DAB substrate chromogen solution was applied to the sections and slides were incubated in the dark at room temperature for $5 \mathrm{~min}$. Mayer's hematoxylin stain was used as a counterstain, and slides were dehydrated and mounted.

Staining was evaluated as described previously $[14,15]$. Briefly, two pathologists who were unaware of the clinical data scored immunohistochemical expression in a semiquantitative fashion. Expression levels were assessed by evaluating the percentage of the cell that was stained, and recorded as absent, weakly, moderately, or markedly positive. (5-25\% indicated weakly, $25-50 \%$ indicated moderately, $>50 \%$ indicated markedly) Using light microscopy, the mean percentage of $\backslash$ positively stained cells in each section was calculated from three dense, medium, and light staining areas. In each area, the percentage of brown stained cells was calculated from the total number of countable cells in five high power fields. Therefore, expression scoring was determined to be discernible and reproducible.

\section{Statistical analyses}

Kruskal-Wallis $\mathrm{H}$ tests were employed to evaluate differences in the amount of COX-2 and Bcl-2 expression among control, CC, CGTP, CGIT and ADC specimens. To further compare the expression of two groups, we performed Mann-Whitney U tests. Spearman's tests were used to analyze the correlation between $\mathrm{COX}-2$ and $\mathrm{Bcl}-2$ expression in CG specimens. P values less than 0.05 were considered significant, and all $\mathrm{P}$ values are two-sided. All analyses were performed using SPSS version 13.0 (SPSS, USA).

\section{Results}

The immunohistochemical staining results are summarized in Table 1, and typical examples from the CGIT and ADC groups are shown in Figure 1. There were significant differences in COX-2 and $\mathrm{Bcl}-2$ expression among the five groups $\left(\chi^{2}=58.917, p=0.000 ; \chi^{2}=50.993, p=0.000\right.$, respectively). The ADC group showed the highest levels of COX-2 and $\mathrm{Bcl}-2$ expression compared to the other groups ( $\mathrm{p}<0.05)$. COX-2 and Bcl-2 expression levels were higher in the CGIT group compared to the CGTP group 
Table 1 Immunohistochemical staining levels in control, CC, CGTP, CGIT, ADC groups

\begin{tabular}{|c|c|c|c|c|c|c|c|c|c|c|}
\hline \multirow{2}{*}{$\begin{array}{l}\text { Levels of } \\
\text { expression }\end{array}$} & \multicolumn{5}{|c|}{ COX-2 } & \multicolumn{5}{|c|}{ Bcl-2 } \\
\hline & Control & $\mathrm{CC}$ & CGTP & CGIT & $A D C$ & Control & $\mathrm{CC}$ & CGTP & CGIT & $A D C$ \\
\hline Absent & 8 (88.9\%) & 9 (81.8\%) & 1 (3.3\%) & $0(0 \%)$ & $0(0 \%)$ & 8 (88.9\%) & $6(54.5 \%)$ & 11 (36.7\%) & $0(0 \%)$ & $0(0 \%)$ \\
\hline Weak & 1 (11.1\%) & 2 (18.2\%) & $18(60.0 \%)$ & $3(10.0 \%)$ & $0(0 \%)$ & 1 (11.1\%) & $4(36.4 \%)$ & 18 (60.0\%) & $9(30.0 \%)$ & $0(0 \%)$ \\
\hline Moderate & $0(0 \%)$ & $0(0 \%)$ & 11 (36.7\%) & 22 (73.3\%) & 1 (25.0\%) & $0(0 \%)$ & 1 (9.1\%) & $1(3.3 \%)$ & $20(66.7 \%)$ & $2(50.0 \%$ \\
\hline Marked & $0(0 \%)$ & $0(0 \%)$ & $0(0 \%)$ & $5(16.7 \%)$ & $3(75.0 \%)$ & $0(0 \%)$ & $0(0 \%)$ & $0(0 \%)$ & $1(3.3 \%)$ & $2(50.0 \%$ \\
\hline
\end{tabular}

CC: Chronic cystitis; CGTP: Typical type of cystitis glandularis; CGIT: Intestinal type of cystitis glandularis; ADC: Adenocarcinoma of bladder.

$(\mathrm{Z}=-4.473, \mathrm{p}=0.000 ; \mathrm{Z}=-5.580, \mathrm{p}=0.000$, respectively), and both of these groups showed higher COX-2 expression compared to the $\mathrm{CC}$ group $(\mathrm{Z}=-5.227, \mathrm{p}=0.000$; $\mathrm{Z}=-4.482, \mathrm{p}=0.000$, respectively). However, the difference in Bcl-2 expression between the CGTP and CC groups was not significant $(Z=-0.752, \mathrm{p}=0.452)$. COX-2 and $\mathrm{Bcl}-2$ levels were not different between the control and CC groups $(Z=-0.429, p=0.668 ; Z=-1.658, p=0.097$, respectively).

To determine whether increased COX-2 expression was associated with up-regulation of the anti-apoptotic protein Bcl-2 in CG patients, Spearman's tests were performed to analyze the correlation between expression of the two proteins in specimens. We found that COX-2 and Bcl-2 expression were positively related $(r=0.648$, $\mathrm{p}=0.000)$.

\section{Discussion}

COX-2 overexpression contributes to tumorigenesis through multiple and complex mechanisms [9]. Liu et al. reported that strong COX-2 expression in murine mammary gland epithelial cells resulted in breast tumor development [16]. Nevertheless, other mouse models of skin carcinogenesis found that COX-2 plays a role in tumor promotion rather than initiation $[17,18]$. In the current study, we observed that COX-2 expression in CGIT and CGTP specimens were significantly higher compared to CC and control. CGIT tissue had a stronger COX-2 expression compared to CGTP. Additionally, COX-2 was aberrantly expressed in ADC tissue. These data suggest that the COX-2 overexpression in these two CG subtypes likely contribute to sensitizing premalignant lesions to genotoxic carcinogens.

Apoptosis is a programmed cell death process that depends on a balance of pro- and anti-apoptotic factors. It is vital for tissue homeostasis and defense against pathogens. Decreased apoptosis has been observed in premalignant lesions. It is well known that COX-2 overexpression increases expression of the proto-oncogene Bcl-2 and inhibits apoptosis [19]. Bcl-2, the first apoptotic regulator
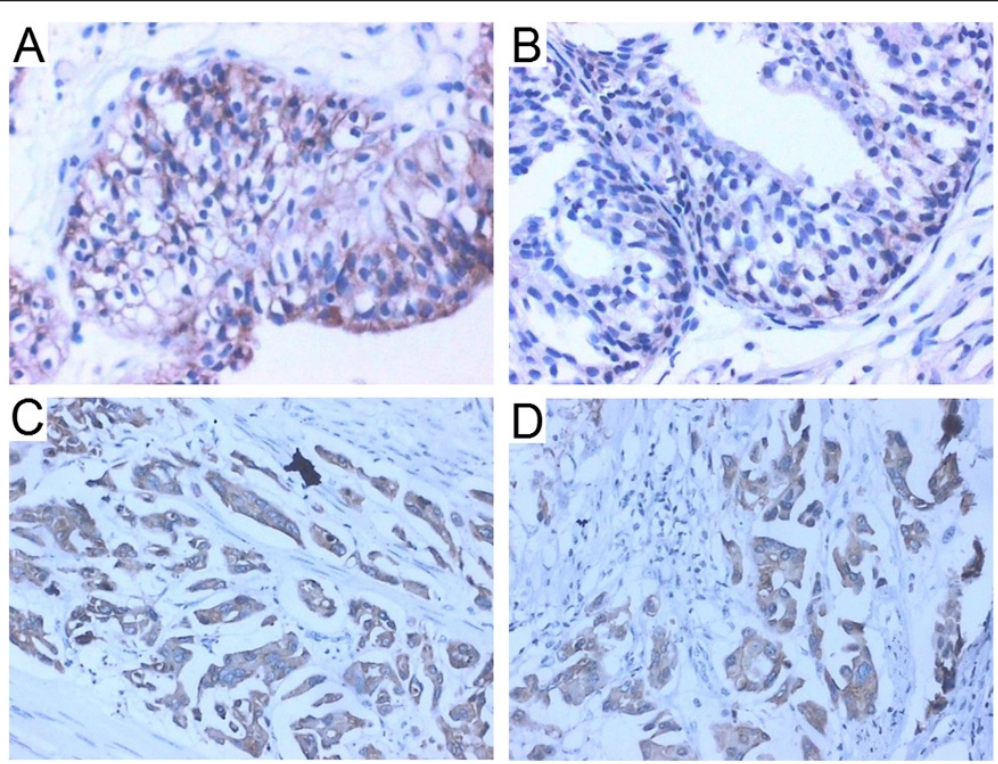

Figure 1 Immunohistochemical staining to evaluate Cox-2 and Bcl-2 localization (original magnification 400x). A. Cox-2 expression in CGIT. B. BCl-2 expression in CGIT. C. COX-2 expression in ADC. D. BCl-2 expression in ADC. 
identified, was originally discovered as the defining oncogene in follicular lymphomas [20]. Unlike other oncogenes that increased cell proliferation, Bcl-2 inhibited programmed cell death and affected the apoptotic pathway, which are critical for cancer development [19]. Our results demonstrate that Bcl-2 expression in CGIT, but not in CGTP, was significantly higher compared to CC and control. However, ADC cases had the highest levels of Bcl-2. Additionally, Bcl-2 expression in CG cases was positively related to COX-2 expression, similar to the report by Tsujii et al. [21]. These data suggest that impaired apoptosis may occur both in both CG subtypes and play a critical role in premalignant lesions.

Several reports have shown that adenocarcinoma of the bladder is associated with CG [22-25]. However, after more than ten years of data tracking, Corica et al. reported that none of the 53 patients with CG developed bladder cancer [26]. As a result, the association between CG and adenocarcinoma remains unclear. Although inflammation is regarded as a possible initiator of cancer $[27,28]$ and $\mathrm{COX}-2$ and $\mathrm{Bcl}-2$ expression were reported to be tumor initiators or promoters [28], the malignant potential of CG should be examined in future studies.

In conclusion, COX-2 and Bcl-2 overexpression in CG suggests that CG, particularly the intestinal type, may be a premalignant lesion that converts into a tumor in the presence of carcinogens. However, further molecular and clinical studies are needed to test this hypothesis.

\section{Conclusion}

COX-2 and Bcl-2 overexpression in CG suggests that CG, particularly the intestinal type, may be a premalignant lesion that converts into a tumor in the presence of carcinogens.

\section{Competing interests}

The authors declare that they have no competing interests.

\section{Authors' contributions}

ZL, GG, and RF performed the molecular genetic studies, analyzed the sequence alignment, and drafted the manuscript. DW performed the immunoassays. BS helped with sequence alignment. XW designed the study and performed the statistical analyses. YC and JL conceived the study, designed the study, and coordinated and drafted the manuscript. XJ conceived the study and designed, coordinated, and drafted the manuscript. All authors read and approved the final manuscript.

\section{Acknowledgements}

The Science and Technology Planning Project of Zhenjiang (SH2008052. Jiangsu Province, China) supported this work.

\section{Author details}

${ }^{1}$ Department of Urology, The No.2 People's Hospital of Zhenjiang, affiliated with Jiangsu University, Zhenjiang, China. ${ }^{2}$ Department of Epidemiology, Jiangsu University, Zhenjiang, China. ${ }^{3}$ Department of Urology, The First Affiliated Hospital of Nanjing Medical University, 300 Guangzhou Road, Nanjing 210029, China.
Received: 7 July 2013 Accepted: 27 December 2013

Published: 3 January 2014

\section{References}

1. Bell TE, Wendel RG: Cystitis glandularis: benign or malignant. J Urol 1968, 100:462-465.

2. Davies G, Castro JE: Cystitis glandularis. Urology 1977, 10:128-129.

3. Sung MT, Lopez-Beltran A, Eble JN, et al: Divergent pathway of intestinal metaplasia and cystitis glandularis of the urinary bladder. Mod Pathol 2006, 19:1395-1401.

4. Capozza N, Collura G, Nappo S, de Dominicis M, Francalanci P, Caione P: Cystitis glandularis in children. BJU Int 2005, 95:411-413.

5. Mukhopadhyay S, Taylor W: Pathologic quiz case: bladder tumor in a 41-year-old man. Cystitis glandularis of intestinal type with mucin extravasation. Arch Pathol Lab Med 2004, 128:e89-e90.

6. Lopez-Beltran A, Cheng L: Histologic variants of urothelial carcinoma: differential diagnosis and clinical implications. Hum Pathol 2006, 37:1371-1388.

7. Bryan RT, Nicholls JH, Harrison RF, Jankowski JA, Wallace DM: The role of beta-catenin signaling in the malignant potential of cystitis glandularis. J Urol 2003, 170:1892-1896.

8. Cao Y, Prescott SM: Many actions of cyclooxygenase-2 in cellular dynamics and in cancer. J Cell Physiol 2002, 190:279-286.

9. Margulis V, Shariat SF, Ashfaq R, et al: Expression of cyclooxygenase-2 in normal urothelium, and superficial and advanced transitional cell carcinoma of bladder. J Urol 2007, 177:1163-1168.

10. Tanji N, Kikugawa T, Yokoyama M: Immunohistochemical study of cyclooxygenases in prostatic adenocarcinoma; relationship to apoptosis and Bcl-2 protein expression. Anticancer Res 2000, 20:2313-2319.

11. Hixson $\sqcup$, Alberts DS, Krutzsch M, et al: Anti-proliferative effect of nonsteroidal anti-inflammatory drugs against human colon cancer cells. Cancer Epidemiol Biomarkers Prev 1994, 3:433-438.

12. Hida T, Yatabe $Y$, Achiwa $H$, et al: Increased expression of cyclooxygenase 2 occurs frequently in human lung cancers, specifically in adenocarcinomas. Cancer Res 1998, 58:3761-3764.

13. Al-Shibli Kl, Mohammed HA, Mikalsen KS: Sentinel lymph nodes and breast carcinoma: analysis of 70 cases by frozen section. Ann Saudi Med 2005, 25:111-114.

14. Abdulamir AS, Hafidh RR, Kadhim HS, Abubakar F: Tumor markers of bladder cancer: the schistosomal bladder tumors versus non-schistosomal bladder tumors. J Exp Clin Cancer Res 2009, 28:27.

15. Routh JC, Ashley RA, Sebo TJ, et al: B7-H1 expression in Wilms' tumor: correlation with tumor biology and disease recurrence. J Urol 2008, 179:1954-1959. discussion 1959-60.

16. Liu CH, Chang SH, Narko K, et al: Overexpression of cyclooxygenase-2 is sufficient to induce tumorigenesis in transgenic mice. J Biol Chem 2001, 276:18563-18569.

17. Muller-Decker K, Neufang G, Berger I, Neumann M, Marks F, Furstenberger G: Transgenic cyclooxygenase-2 overexpression sensitizes mouse skin for carcinogenesis. Proc Natl Acad Sci U S A 2002, 99:12483-12488.

18. Oshima M, Dinchuk JE, Kargman SL, et al: Suppression of intestinal polyposis in Apc delta716 knockout mice by inhibition of cyclooxygenase 2 (COX-2). Cell 1996, 87:803-809.

19. Adams JM, Cory S: The BCl-2 apoptotic switch in cancer development and therapy. Oncogene 2007, 26:1324-1337.

20. Cory S, Adams JM: The Bcl2 family: regulators of the cellular life-or-death switch. Nat Rev Cancer 2002, 2:647-656.

21. Tsujii M, DuBois RN: Alterations in cellular adhesion and apoptosis in epithelial cells overexpressing prostaglandin endoperoxide synthase 2 . Cell 1995, 83:493-501.

22. Bullock PS, Thoni DE, Murphy WM: The significance of colonic mucosa (intestinal metaplasia) involving the urinary tract. Cancer 1987, 59:2086-2090.

23. Edwards PD, Hurm RA, Jaeschke WH: Conversion of cystitis glandularis to adenocarcinoma. J Urol 1972, 108:568-570.

24. Lin Jl, Yong HS, Tseng CH, Marsidi PS, Choy C, Pilloff B: Diffuse cystitis glandularis. Associated with adenocarcinomatous change. Urology 1980, 15:411-415.

25. Susmano $D$, Rubenstein $A B$, Dakin AR, Lloyd FA: Cystitis glandularis and adenocarcinoma of the bladder. J Urol 1971, 105:671-674. 
26. Corica FA, Husmann DA, Churchill BM, et al: Intestinal metaplasia is not a strong risk factor for bladder cancer: study of 53 cases with long-term follow-up. Urology 1997, 50:427-431.

27. Pawar R, Vijayalakshmy AR, Khan S, LFA AL: Primary neuroendocrine carcinoma (Merkel's cell carcinoma) of the vulva mimicking as a Bartholin's gland abscess. Ann Saudi Med 2005, 25:161-164.

28. Ghosh N, Chaki R, Mandal V, Mandal SC: COX-2 as a target for cancer chemotherapy. Pharmacol Rep 2010, 62:233-244.

doi:10.1186/1471-2490-14-2

Cite this article as: Li et al:: Cyclooxygenase-2 and B-cell lymphoma-2 expression in cystitis glandularis and primary vesicle adenocarcinoma. BMC Urology 2014 14:2.

\section{Submit your next manuscript to BioMed Central and take full advantage of:}

- Convenient online submission

- Thorough peer review

- No space constraints or color figure charges

- Immediate publication on acceptance

- Inclusion in PubMed, CAS, Scopus and Google Scholar

- Research which is freely available for redistribution 